\title{
Association between dose of catecholamines and markers of organ injury early after out-of-hospital cardiac arrest
}

Katarzyna Czerwińska-Jelonkiewicz ${ }^{1,2}$, Alice Wood $^{3}$, Allan Bohm Przemysław Kwasiborski ${ }^{5}$, Anna Oleksiak ${ }^{6}$, Robert Ryczek ${ }^{7}$, Johannes Grand ${ }^{8}$, Tavazzi Guido $^{9}$, Alessandro Sionis ${ }^{10}$, Janina Stępińska ${ }^{6}$

${ }^{1}$ Division of Cardiology, Andrzej Frycz Modrzewski Krakow University, Krakow, Poland

${ }^{2}$ Intensive Therapy Unit, Harefield Hospital, Royal Brompton and

Harefield NHS Foundation Trust, London, United Kingdom

${ }^{3}$ University Hospitals of Leicester, United Kingdom

${ }^{4}$ Department of Acute Cardiology, National Institute of Cardiovascular Diseases, Bratislava, Slovakia ${ }^{5}$ Third Department of Internal Diseases and Cardiology, Warsaw Medical University, Warsaw, Poland

${ }^{6}$ Department of Intensive Cardiac Therapy, National Institute of Cardiology, Warsaw, Poland

${ }^{7}$ Department of Cardiology, Military Institute of Medicine, Warsaw, Poland

${ }^{8}$ Department of Cardiology, University Hospital of Copenhagen, Denmark

${ }^{9}$ Department of Clinical Surgical, Diagnostic and Pediatric Sciences, University of Pavia, Italy

${ }^{10}$ Intensive Cardiac Care Unit Cardiology Department Hospital de la Santa Creu i Sant Pau, Barcelona, Spain

\begin{abstract}
Background: Catecholamines are recommended as first-line drugs to treat hemodynamic instability after out-of-hospital cardiac arrest (OHCA). The benefit-to-risk ratio of catecholamines is dose dependent, however, their effect on metabolism and organ function early after OHCA has not been investigated. Methods: The Post-Cardiac Arrest Syndrome (PCAS) pilot study was a prospective, observational, multicenter study. The primary outcomes of this analysis were association between norepinephrine/ /cumulative catecholamines doses and neuron specific enolase (NSE)/lactate concentration over the first 72 hours after resuscitation. The association was adjusted for proven OHCA mortality predictors and verified with propensity score matching (PSM).

Results: Overall 148 consecutive OHCA patients; aged 18-91 (62.9 \pm 15.27$), 41$ (27.7\%) being female, were included. Increasing norepinephrine and cumulative catecholamines doses were significantly associated with higher NSE concentration on admission $(r=0.477, p<0.001 ; r=0.418, p<0.001)$ and at 24 hours after OHCA $(r=0.339, p<0.01 ; r=0.441, p<0.001)$ as well as with higher lactate concentration on admission $(r=0.404, p<0.001 ; r=0.280, p<0.01)$, at 24 hours $(r=0.476, p<0.00$; $r=0.487, p<0.001)$ and 48 hours $(r=0.433, p<0.01 ; r=0.318, p=0.01)$ after OHCA. The associations remained significant up to 48 hours in non-survivors after PSM.

Conclusions: Increasing dose of catecholamines is associated with higher lactate and NSE concentration, which may suggest their importance for tissue oxygen delivery, anaerobic metabolism, and organ
\end{abstract} function early after OHCA. (Cardiol J)

Key words: catecholamines, cardiac arrest, out-of-hospital cardiac arrest, metabolism after cardiac arrest, organ failure after cardiac arrest

Address for correspondence: Assoc. Prof. Katarzyna Czerwińska-Jelonkiewicz, MD, PhD, Intensive Therapy Unit, Harefield Hospital, Royal Brompton and Harefield NHS Foundation Trust, Hill End Rd, Harefield, Uxbridge UB9 6JH, London, United Kingdom, tel: +44(0) 1895823 737, e-mail: kasia_czerwinska@vp.pl

Received: 16.07.2021 Accepted: 10.10.2021 Early publication date: 28.12.2021

This article is available in open access under Creative Common Attribution-Non-Commercial-No Derivatives 4.0 International (CC BY-NC-ND 4.0) license, allowing to download articles and share them with others as long as they credit the authors and the publisher, but without permission to change them in any way or use them commercially. 


\section{Introduction}

Patients resuscitated from out-of-hospital cardiac arrest (OHCA) are predominantly hemodynamically unstable early in the course of post-cardiac arrest syndrome (PCAS), frequently requiring continuous support of exogenous catecholamines, which are recommended as the first-line drugs to optimize cardiac output, mean arterial pressure and organ perfusion [1-3]. However, the therapeutic window for catecholamines is narrow, with a low threshold for augmentation of endogenous adrenergic stress and adverse sympathetic nerve system stimulation [4-6]. The toxicity of catecholamines to the cardiovascular system is well established and has been linked to adverse outcomes in patients with cardiovascular diseases [4, 7-10]. However, the vulnerability of other organs to catecholamines excess has been investigated only by small, single center analyzes of septic and the critically ill that were focused on single organ dysfunction [11-14]. High plasma catecholamine concentration has been demonstrated to induce pulmonary edema and to be a risk factor for acute lung injury in a critical setting $[4,11]$. Exogenous catecholamine administration reduces gastrointestinal blood flow and motility, indicating splanchnic ischemia $[4,12]$. Sustained elevated levels of norepinephrine have been implicated in hepatocellular dysfunction and altered hepatocyte integrity $[4,13]$. A detrimental impact of catecholamines on metabolism has also been reported, manifesting in an excessive oxygen consumption and metabolic acidosis that results in inflammatory and coagulatory system activation and organ dysfunction [11-15]. Despite being the first line treatment after OHCA, the effect of exogenous catecholamines administration on metabolism and organ function in the early and intermediate phases of PCAS has not been investigated.

Therefore, the aim of the present study was to investigate the association between catecholamines dose over the first 72 hours of admission, and selected laboratory parameters, being surrogate endpoints for impaired tissue oxygen delivery, anaerobic metabolism and organ injury, in patients admitted after OHCA of suspected cardiac origin.

\section{Methods}

\section{Study design}

The Post-Cardiac Arrest Syndrome (PCAS) pilot study was a prospective, observational, multicenter project [16]. Inclusion criteria were: $\mathrm{OHCA}$ of suspected cardiac cause, aged 18 years or older, admission after return of spontaneous circulation (ROSC) and written informed consent obtained from the patient or next of kin as required by local policy. The primary outcomes of the study were: (a) the prevalence and profile of organ failure according to sequential organ failure assessment score (SOFA) score within the first 72 hours after OHCA, (b) in--hospital and short-term mortality. The study was performed in compliance with the Declaration of Helsinki and was approved by local ethics/audit committees of each participating center.

The outcomes of the sub-analysis presented here were lactate and neuron specific enolase (NSE) concentration during the first 72 hours after OHCA. Investigated risk factors were norepinephrine dose $(\mu \mathrm{g} / \mathrm{kg} / \mathrm{min})$ and cumulative dose of catecholamines ( $\mu \mathrm{g} / \mathrm{kg} / \mathrm{min})$.

The association was adjusted for proven $\mathrm{OHCA}$ mortality predictors and verified by logarithmic transformation and propensity score matching (PSM) for in-hospital survival with the cohorts' equalization for SOFA score on admission [17].

\section{Data collection}

Demographic and prehospital data regarding the event were systematically collected on admission according to the Utstein guidelines [18]. Detailed laboratory parameters, including ABG and NSE concentration were collected prospectively every 24 hours, starting from the intensive cardiac care unit (ICCU) admission, until 72 hours of ICCU stay. Mean arterial blood pressure, catecholamines administration and their doses were recorded at the same time points of the assessment. All data were anonymized and were entered into the dedicated database.

Dobutamine, dopamine and norepinephrine were used as the first-line agents and epinephrine, vasopressin and milrinone were second-line drugs administered to achieve the target mean arterial and peripheral perfusion pressure. The exact choice of medication as well as the dose on an individual patient level were left to the discretion of the treating physician.

The cumulative catecholamine dose was calculated using the formula: cumulative dose $=$ $=$ norepinephrine $(\mu \mathrm{g} / \mathrm{kg} / \mathrm{min})+$ dopamine $(\mu \mathrm{g} / \mathrm{kg} /$ $/ \mathrm{min} / 2)+$ epinephrine $(\mu \mathrm{g} / \mathrm{kg} / \mathrm{min})$ [19].

\section{Statistical analysis}

Categorical data are presented as numbers and percentages. Continuous variables are presented as means and standard deviations. Normality of data was assessed using the Shapiro-Wilk test. Unpaired Student t-test was used to compare continuous vari- 
ables. The Fisher exact test was used for categorical data. The correlation between continuous variables was assessed using the Pearson correlation coefficient. Univariable and multivariable linear regression analysis was performed to assess associations. Multivariable models included confounding variables (proven predictors of mortality after OHCA), which were initially isolated in comparative analyses, such as mean arterial pressure below $70 \mathrm{mmHg}$, age, bystander response, time to ROSC, initial cardiac rhythm (shockable vs. non-shockable). Estimates are presented together with $95 \%$ confidence intervals (CIs). Subjects with no catecholamines administration in prespecified time points of the assessment were excluded from all analyzes.

Subsequently, a numerical pseudo randomization with PSM with replacement was performed to equalize the study cohorts (in-hospital survivors vs non-survivors) according to SOFA score on admission (Suppl. Fig. 1). The nearest neighbor method was used to match 67 pairs. Wilcoxon paired test was used for comparison of basic demographics and pre-hospital, in-hospital data between the matched groups. Results of lactate and NSE concentrations were log-transformed to normalize their distribution. Subsequently, the Spearman correlation was performed to verify results of the linear regression association between catecholamines and lactate/NSE.

A p value $<0.05$ was considered statistically significant for all tests performed. All statistical analyzes were performed using the StatsDirect statistical software version 3.2.10.

\section{Results}

Overall, 148 consecutive adult patients resuscitated after OHCA and admitted to hospital from October 2017 to February 2019 were included. Subject age ranged from 18 to $91(62.9 \pm 15.27)$ years and $41(27.7 \%)$ were women. Demographics, pre-hospital OHCA data as well as selected laboratory parameters and catecholamine dosages are presented in Table 1. Overall, 68 (46.9\%) inhospital deaths occurred between 0 and 107 (14 \pm $\pm 15.95)$ days of hospitalization. Most of the deaths, $45(66.17 \%)$, occurred within the first 5 days of hospital stay. The main direct cause of in-hospital deaths was cardiogenic shock, noted in 46 (67.6\%) of the cases, followed by central nervous system injury reported in $20(29.4 \%)$ of the deaths.

Norepinephrine was the most used catecholamine during the first 72 hours of hospitalization. Dobutamine and dopamine were respectively the second (on admission: 35 (23.6\%), 24 h: 23 (17.8\%),
48 h: 16 (13.1\%), $72 \mathrm{~h}: 13(11.6 \%))$ and the third (on admission: 24 (16.2\%), $24 \mathrm{~h}: 25$ (19.5\%), $48 \mathrm{~h}$ : 21 (17.2\%), $72 \mathrm{~h}: 9$ (8.0\%) most frequently used. Lactate and NSE concentration as well as catecholamines dose were significantly higher among those who died during the hospitalization in comparison to the survivors up to 48 hours from admission (Table 1).

The results of PSM for initial SOFA score are presented in Table 2 . The cohorts were well matched in terms of demographics and in-hospital data, including cause of OHCA and therapeutic interventions, however in-hospital survivors had persistently shorter time to ROSC and their initial rhythm was more frequently shockable (Table 2).

\section{Catecholamines dose and metabolic derangement}

Simple linear regression showed increasing dose of norepinephrine and cumulative catecholamines dose were significantly correlated with increased lactate concentration until 48 hours after the event, with the strongest correlation at 24 hours after OHCA (Figs. 1,2). Similarly, an increasing dose of norepinephrine was significantly correlated with NSE concentration on admission $(\mathrm{r}=0.477 ; \mathrm{p}=0.0001), 24$ hours $(\mathrm{r}=0.339$; $\mathrm{p}=0.009)$ and 48 hours after admission $(\mathrm{r}=0.332$; $\mathrm{p}=0.036$ ) (Fig. 3). Increasing cumulative dose of catecholamines was correlated with increased NSE concentration on admission $(r=0.418$, $\mathrm{p}<0.001)$ and at 24 hours after OHCA $(\mathrm{r}=0.441$, $\mathrm{p}<0.0001$ ) (Fig. 4).

Multiple linear regression analysis confirmed that increasing norepinephrine dose and cumulative catecholamine dose were independently associated with higher lactate concentration during the first 48 hours after OHCA (Figs. 1, 2). Furthermore, increasing dose of catecholamine were independently associated with higher NSE concentration on admission and 24 hours after OHCA (Figs. 3, 4). The Spearman correlation after logarithmic transformation and PSM confirmed a significant association between catecholamine doses and lactate within the first 48 hours after OHCA as well as between catecholamine doses and NSE within the first 24 hours, among patients who died during the index hospitalization (Table 3).

\section{Institutional board review statement and informed consent statement}

The study was conducted according to the guidelines of the Declaration of Helsinki and ap- 
Table 1. Clinical characteristics of the study population, pre-hospital data of out-of-hospital cardiac arrest $(\mathrm{OHCA})$, selected laboratory derangements and catecholamines doses during the first 72 hours after OHCA.

\begin{tabular}{|c|c|c|c|}
\hline & Survivors $(n=80)$ & Non-survivors $(n=68$ ) & $\mathbf{P}$ \\
\hline \multicolumn{4}{|l|}{ Demographics } \\
\hline Age [years] & 59.5 & $65.57 \pm 14.87$ & 0.01 \\
\hline Males & $21(27.3 \%)$ & $20(29.4 \%)$ & 0.77 \\
\hline Coronary artery disease & $22(28.6 \%)$ & $18(27.7 \%)$ & 0.91 \\
\hline Previous myocardial infarction & $16(20.8 \%)$ & $12(18.5 \%)$ & 0.73 \\
\hline Congestive heart failure & $10(12.9 \%)$ & $10(15.4 \%)$ & 0.68 \\
\hline Bystander response & $54(72 \%)$ & $43(63.3 \%)$ & 0.26 \\
\hline Bystander response time [min] & $6.45 \pm 4.15$ & $7.37 \pm 3.89$ & 0.07 \\
\hline Time to ROSC [min] & $16.58 \pm 2.37$ & $24.2 \pm 12.55$ & $<0.0001$ \\
\hline Initial shockable rhythm & $65(86.7 \%)$ & $37(54.4 \%)$ & $<0.0001$ \\
\hline Target temperature management & $53(68.8 \%)$ & $46(67.6 \%)$ & 0.88 \\
\hline \multicolumn{4}{|c|}{ Laboratory derangements and catecholamines on admission } \\
\hline Lactate $[\mathrm{mmol} / \mathrm{L}]$ & $4.05 \pm 11.33$ & $7.63 \pm 4.9$ & $<0.001$ \\
\hline NSE $[\mathrm{ng} / \mathrm{mL}]$ & $30.66 \pm 16.45$ & $77.4 \pm 49.58$ & $<0.001$ \\
\hline Norepinephrine & $51(63.6 \%)$ & $37(54.4 \%)$ & 0.26 \\
\hline Norepinephrine dose $[\mu \mathrm{g} / \mathrm{kg} / \mathrm{min}]$ & $0.09 \pm 0.11$ & $0.54 \pm 0.5$ & 0.0002 \\
\hline Cumulative catecholamines dose $[\mu \mathrm{g} / \mathrm{kg} / \mathrm{min}]$ & $1.56 \pm 3.35$ & $6.39 \pm 14.0$ & 0.05 \\
\hline \multicolumn{4}{|c|}{ Laboratory derangements and catecholamines $24 \mathrm{~h}$ after admission } \\
\hline Lactate $[\mathrm{mmol} / \mathrm{L}]$ & $1.66 \pm 1.51$ & $3.78 \pm 3.3$ & $<0.001$ \\
\hline NSE $[\mathrm{ng} / \mathrm{mL}]$ & $30.05 \pm 13.5$ & $95.11 \pm 67.17$ & $<0.001$ \\
\hline Norepinephrine & $47(58.6 \%)$ & $43(63.4 \%)$ & 0.59 \\
\hline Norepinephrine dose $[\mu \mathrm{g} / \mathrm{kg} / \mathrm{min}]$ & $0.10 \pm 0.22$ & $0.25 \pm 0.36$ & 0.0001 \\
\hline Cumulative catecholamines dose $[\mu \mathrm{g} / \mathrm{kg} / \mathrm{min}]$ & $1.24 \pm 2.16$ & $7.22 \pm 7.24$ & 0.0002 \\
\hline \multicolumn{4}{|c|}{ Laboratory derangements and catecholamines $48 \mathrm{~h}$ after admission } \\
\hline Lactate $[\mathrm{mmol} / \mathrm{L}]$ & $1.22 \pm 0.67$ & $2.17 \pm 1.92$ & $<0.0001$ \\
\hline NSE $[\mathrm{ng} / \mathrm{mL}]$ & $34.06 \pm 55.53$ & $141.41 \pm 130.79$ & $<0.0001$ \\
\hline Norepinephrine & $29(36.5 \%)$ & $30(44.0 \%)$ & 0.37 \\
\hline Norepinephrine dose $[\mu \mathrm{g} / \mathrm{kg} / \mathrm{min}]$ & $0.04 \pm 0.08$ & $0.59 \pm 0.24$ & 0.0007 \\
\hline Cumulative catecholamines dose $[\mu \mathrm{g} / \mathrm{kg} / \mathrm{min}]$ & $0.63 \pm 0.46$ & $8.56 \pm 21.77$ & 0.02 \\
\hline \multicolumn{4}{|c|}{ Laboratory derangements and catecholamines $72 \mathrm{~h}$ after admission } \\
\hline Lactate $[\mathrm{mmol} / \mathrm{L}]$ & $3.19 \pm 3.53$ & $4.27 \pm 4.09$ & 0.12 \\
\hline NSE $[\mathrm{ng} / \mathrm{mL}]$ & $38.8 \pm 68.93$ & $103.45 \pm 81.42$ & $<0.0001$ \\
\hline Norepinephrine & $14(17.8 \%)$ & $22(33.3 \%)$ & 0.06 \\
\hline Norepinephrine dose $[\mu \mathrm{g} / \mathrm{kg} / \mathrm{min}]$ & $0.014 \pm 0.05$ & $0.37 \pm 0.13$ & 0.01 \\
\hline Cumulative catecholamine dose $[\mu \mathrm{g} / \mathrm{kg} / \mathrm{min}]$ & $0.39 \pm 1.37$ & $5.68 \pm 16.9$ & 0.01 \\
\hline
\end{tabular}

NSE - neuron specific enolase; ROSC — return of spontaneous circulation

proved by the Institutional Review Board of each participating center. Ethics Committee approval of Leading Center of the Primary Investigator Number: 83/WIM/2017.

Informed consent was obtained from all subjects or the next of kin involved in the study.

\section{Discussion}

Life-threatening conditions such as OHCA and PCAS are some of the most potent triggers of adrenergic stress [1, 2, 4]. Plasma concentration of endogenous norepinephrine and epinephrine in- 
Table 2. Comparison of selected demographics, pre-hospital and in-hospital data after propensity score matching between in-hospital survivors vs. non-survivors.

\begin{tabular}{|c|c|c|c|c|c|c|c|}
\hline \multirow[t]{2}{*}{ Variables } & \multicolumn{3}{|c|}{ Survivors } & \multicolumn{3}{|c|}{ Non-survivors } & \multirow[t]{2}{*}{$\mathbf{P}$} \\
\hline & $\mathbf{N}$ pairs & Mediana & IQR & $\mathbf{N}$ pairs & Mediana & IQR & \\
\hline \multicolumn{8}{|l|}{ Demographics and pre-hospital data } \\
\hline SOFA score on admission & 68 & 7.0 & $5.5-8.0$ & 68 & 7,0 & 6.5 & 0.55 \\
\hline Age [year] & 68 & 64.0 & $55.0-70.5$ & 67 & 67.0 & 58.0 & 0.13 \\
\hline Males [\%] & 57 & 83.80 & & 48 & 70.6 & & 0.07 \\
\hline Coronary artery disease [\%] & 21 & 30.90 & & 18 & 27.70 & & 0.7 \\
\hline Myocardial infarction [\%] & 13 & 19.10 & & 12 & 18.40 & & 0.9 \\
\hline Congestive heart failure [\%] & 11 & 16.20 & & 10 & 15.40 & & 0.9 \\
\hline Bystander response [\%] & 47 & 70.10 & & 43 & 63.20 & & 0.4 \\
\hline EMS response time [min] & 65 & 9:00 & $6: 0-14: 0$ & 62 & 10:00 & $8: 0-13: 0$ & 0.36 \\
\hline Shockable rhythm [\%] & 60 & 92.30 & & 37 & 54.40 & & $<0.001$ \\
\hline Time to ROSC [min] & 67 & 19:00 & $12: 0-29: 0$ & 63 & $30: 10$ & 22:0-43:0 & $<0.01$ \\
\hline \multicolumn{8}{|c|}{ In-hospital data, causes of OHCA and interventions } \\
\hline GCS on admission & 68 & 3.0 & $3.0-3.0$ & 67 & 3.0 & $3.0-3.0$ & 0.8 \\
\hline TTM minimal temperature & 47 & 34.7 & $33.7-35.5$ & 46 & 34.2 & $33.0-35.3$ & 0.21 \\
\hline Acute coronary syndrome [\%] & 29 & 42.60 & & 33 & 48.50 & & 0.49 \\
\hline Primary arrhythmia [\%] & 30 & 34.10 & & 17 & 25.00 & & 0.2 \\
\hline Pulmonary embolism [\%] & 0 & 0 & & 2 & 2.94 & & 0.1 \\
\hline Aorta dissection [\%] & 0 & 0 & & 1 & 1.47 & & 0.2 \\
\hline Acute heart failure [\%] & 1 & 1.47 & & 4 & 5.97 & & 0.15 \\
\hline Decompensated CHF [\%] & 7 & 10.30 & & 2 & 2.99 & & 0.08 \\
\hline Angiography [\%] & 62 & 91.2 & & 53 & 79.10 & & 0.06 \\
\hline $\mathrm{PCl}[\%]$ & 32 & 48.50 & & 31 & 47 & & 0.9 \\
\hline CABG [\%] & 1 & 1.52 & & 0 & 0 & & 0.2 \\
\hline Mechanical circulatory support [\%] & 6 & 9.10 & & 11 & 16.40 & & 0.2 \\
\hline ICCU stay [days] & 66 & 5.0 & $3.0-8.0$ & 68 & 4.5 & $1.0-8.5$ & 0.08 \\
\hline
\end{tabular}

CABG - coronary artery bypass grafting; CHF — chronic heart failure; EMS — emergency medical system; GCS — Glasgow Coma Score; ICCU - Intensive Cardiac Care Unit; OHCA - out-of-hospital cardiac arrest; PCI — percutaneous coronary intervention; ROSC - return of spontaneous circulation; SOFA score - sequential organ failure assessment; TTM — target temperature management

creased between 10 and 1000-fold during cardiopulmonary resuscitation and remained elevated during PCAS [4]. One of the common features of PCAS is hemodynamic instability, resulting from myocardial stunning and impaired vascular tone $[1,2,4]$. The hemodynamic instability after OHCA leads directly to impaired peripheral perfusion, reduced tissue oxygen delivery and anaerobic metabolism, being a potent risk factor for multiple organ failure and the main direct cause of early death after resuscitation $[1,2,20]$. The myocardial stunning and impaired vaso-regulation due to PCAS are claimed to be reversible and responsive to inotropic and vasoactive agents [21]. Therefore, the principal aim of exogenous catecholamines in this setting is to enhance myocardial contractility and to correct systemic and regional perfusion as well as oxygen delivery and utilization [4-6]. Unfortunately, desensitization, downregulation of beta-adrenoreceptors as well as impaired binding of catecholamines to the receptors during hypoxia and acidosis may lead to a reduced response to exogenous catecholamines, necessitating up titration of their doses keeping in mind commonly known overt side effects of catecholamines [22-26]. In septic shock patients, norepinephrine was shown to increase arterial stiffness, myocardial afterload and cardiac workload, overall worsening left ventricle performance and decreasing perfused capillary density $[8,24]$. Dobutamine was shown to increase cellular metabolism and oxygen consumption and to impair tissue oxygen extraction in sepsis and congestive heart failure [10,25]. Epinephrine in 

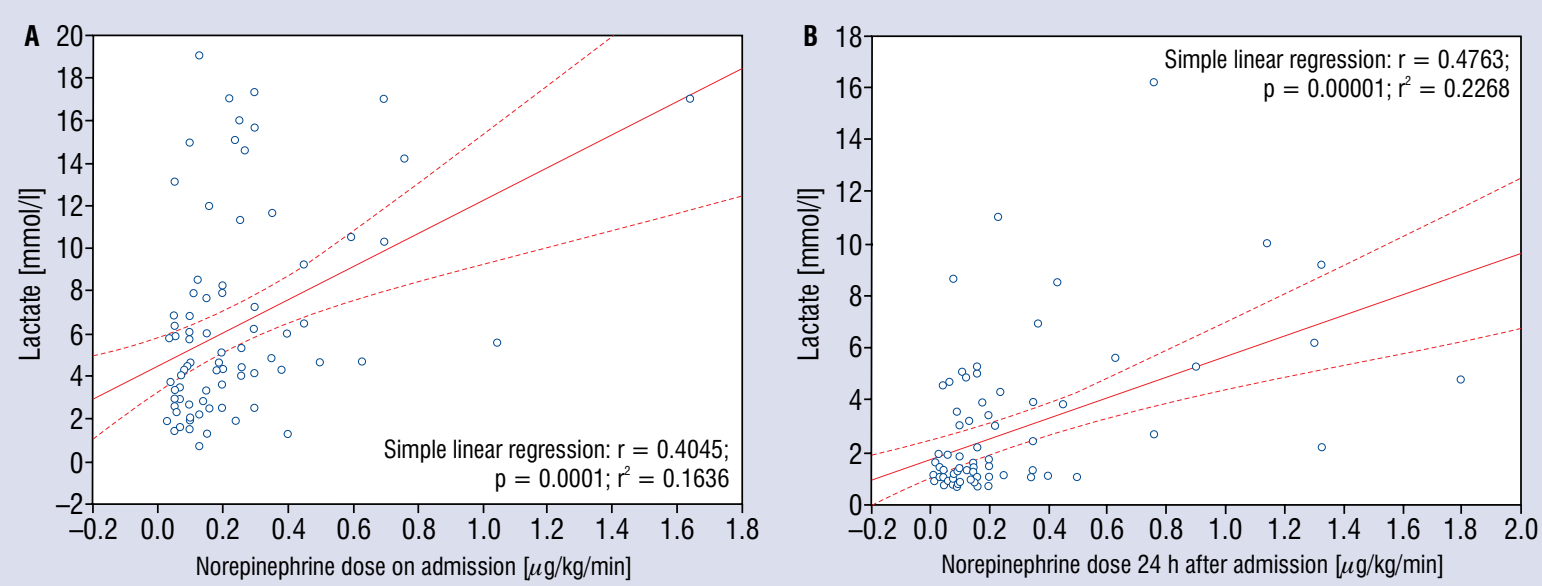

\begin{tabular}{|l|c|c|c|c|}
\hline Multiple regression model & $\boldsymbol{\beta}$ coefficient & $\mathbf{r}$ coefficient & $\mathbf{t}$ Stat & $\mathbf{p}$-value \\
\hline Norepinephrine dose & 2.264 & 0.238 & 2.743 & 0.007 \\
\hline Mean BP $<70 \mathrm{mmHg}$ & 1.736 & 0.186 & 2.117 & 0.03 \\
\hline Age & -0.038 & -0.115 & -1.299 & 0.19 \\
\hline Bystander response & 0.655 & 0.076 & 0.853 & 0.39 \\
\hline Time to ROSC & 12.251 & 0.044 & 0.499 & 0.6 \\
\hline Shockable rhythm & -3.184 & -0.329 & -3.900 & 0.0002 \\
\hline Multiple correlation coefficient & $(\mathrm{R})=0.479$ & $\mathrm{R}^{2}=23.0 \%$ & $\mathrm{Ra}^{2}=19.3 \%$ & $<0.0001$ \\
\hline
\end{tabular}

\begin{tabular}{|l|c|c|c|c|}
\hline Multiple regression model & $\boldsymbol{\beta}$ coefficient & $\mathbf{r}$ coefficient & $\mathbf{t}$ Stat & p-value \\
\hline Norepinephrine dose & 3.283 & 0.36 & 4.138 & $<0.0001$ \\
\hline Mean BP $<70 \mathrm{mmHg}$ & -0.043 & -0.007 & -0.079 & 0.93 \\
\hline Age & 0.031 & 0.17 & 1.849 & 0.06 \\
\hline Bystander response & 0.478 & 0.09 & 0.952 & 0.34 \\
\hline Time to ROSC & 10.789 & 0.065 & 0.688 & 0.49 \\
\hline Shockable rhythm & -0.747 & -0.128 & -1.357 & 0.17 \\
\hline Multiple correlation coefficient & $(\mathrm{R})=0.488$ & $\mathrm{R}^{2}=23.89 \%$ & $\mathrm{Ra}^{2}=19.749 \%$ & $<0.0001$ \\
\hline
\end{tabular}

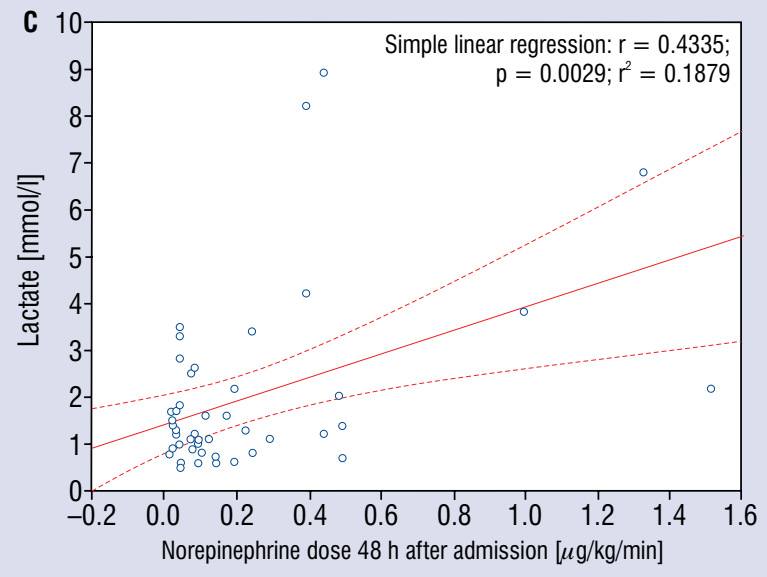

\begin{tabular}{|l|c|c|c|c|}
\hline Multiple regression model & $\boldsymbol{\beta}$ coefficient & $\mathbf{r}$ coefficient & $\mathbf{t}$ Stat & $\boldsymbol{p}$-value \\
\hline Norepinephrine dose & 1.856 & 0.314 & 3.21 & 0.001 \\
\hline Mean BP $<70 \mathrm{mmHg}$ & 0.652 & 0.24 & 2.485 & 0.01 \\
\hline Age & 0.01 & 0.177 & 1.751 & 0.08 \\
\hline Bystander response & 0.52 & 0.18 & 1.784 & 0.07 \\
\hline Time to ROSC & 10.42 & 0.091 & 0.887 & 0.37 \\
\hline Shockable rhythm & -0.269 & -0.82 & -0.805 & 0.4 \\
\hline Multiple correlation coefficient & $(\mathrm{R})=0.557$ & $\mathrm{R}^{2}=31.05 \%$ & $\mathrm{Ra}^{2}=26.65 \%$ & $<0.0001$ \\
\hline
\end{tabular}

Figure 1. A. Association between norepinephrine dose and lactate concentration on admission in the study population; B. Association between norepinephrine dose and lactate concentration 24 hours after admission in the study population; C. Association between norepinephrine dose and lactate concentration 48 hours after admission in the study population; BP — blood pressure; ROSC — return of spontaneous circulation.

comparison to a norepinephrine-dobutamine combination in septic patients has been shown to decrease splanchnic oxygen utilization and enhance anaerobic metabolism leading to acidosis and an increase in lactate concentration [26].

Despite a large number of studies looking at the effect of catecholamines in critical care, there is a paucity of data on their effects on metabolism and organ function in the OHCA population. The outcomes of the present study, and the first ones, to show that catecholamines dose is related to the derangement of biochemical parameters, reflecting their potential adverse impact on metabolism and organ function in the early course of PCAS. Shown herein, that increased norepinephrine dose and cumulative catecholamine dose were independently 


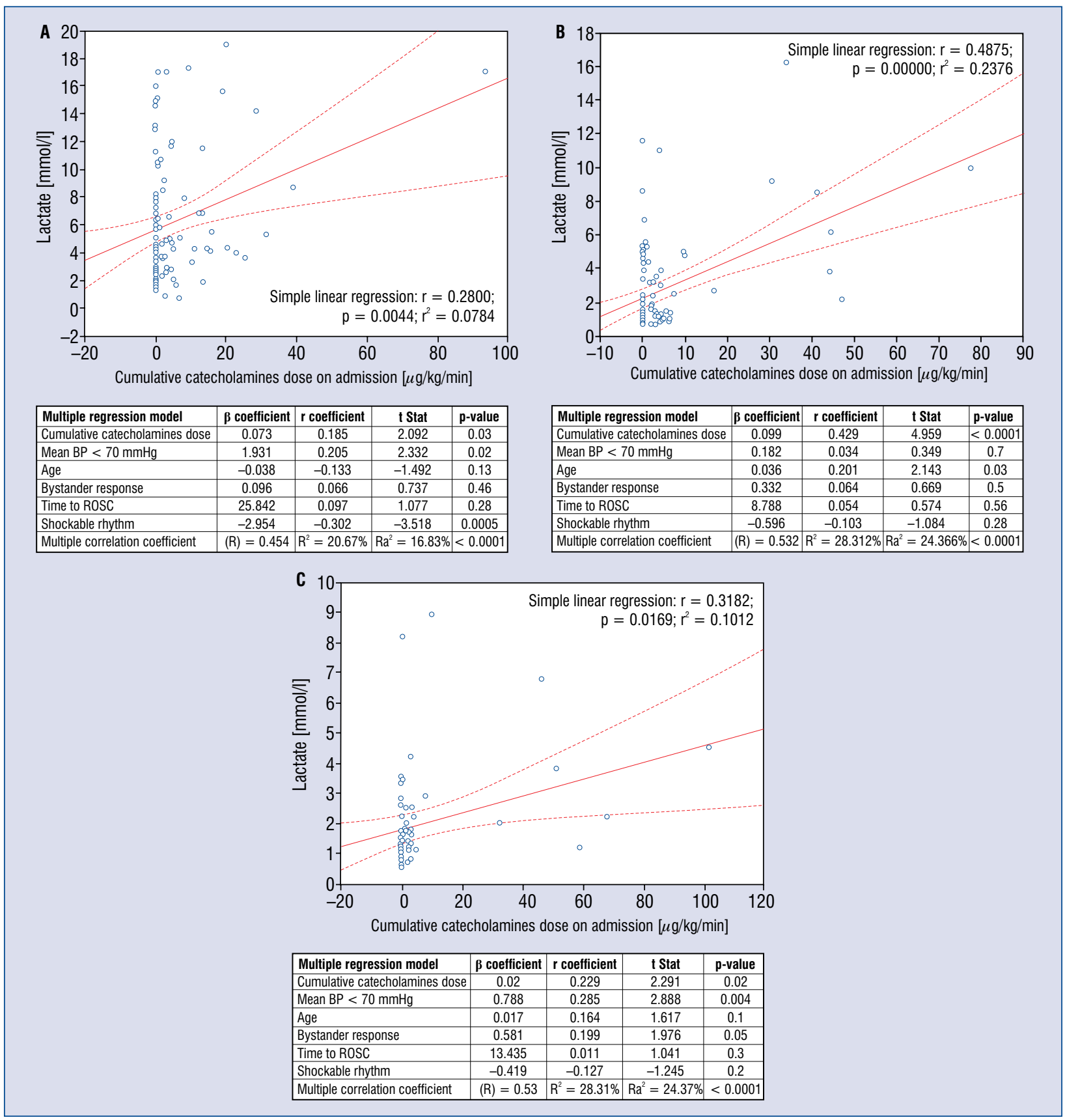

Figure 2. A. Association between cumulative catecholamines dose and lactate concentration on admission in the study population; B. Association between cumulative catecholamines dose and lactate concentration 24 hours after admission in the study population; C. Association between cumulative catecholamines dose and lactate concentration 48 hours after admission in study population; BP — blood pressure; ROSC — return of spontaneous circulation.

associated with increased lactate concentration within the first 48 hours after OHCA, especially in the non-survivor cohort.

Lactate has been established as the best indicator of impaired tissue perfusion, oxygen depletion, and anaerobic metabolism as well as mortality predictor, becoming a fundamental part of the monitoring of the critically ill patient [27-29]. Given the proven predictive value of lactate for organ failure and for poor prognosis in OHCA, septic shock, trauma and high-risk surgery, the relationship revealed herein, between catecholamine dose and lactate concentration after OHCA seems to be of particular importance. 

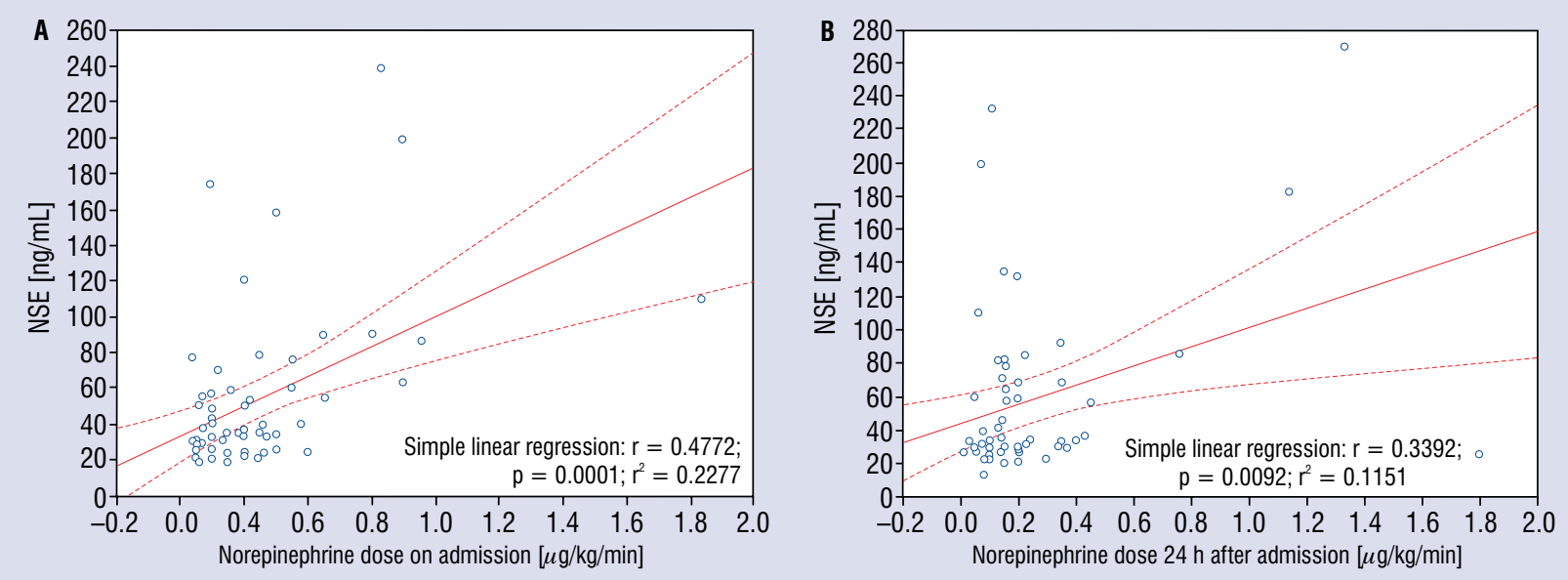

\begin{tabular}{|l|c|c|c|c|}
\hline Multiple regression model & $\boldsymbol{\beta}$ coefficient & $\mathbf{r}$ coefficient & $\mathbf{t}$ Stat & $\boldsymbol{p}$-value \\
\hline Norepinephrine dose & 63.833 & 0.466 & 4.469 & $<0.0001$ \\
\hline Mean BP $<70 \mathrm{mmHg}$ & -0.366 & -0.002 & -0.021 & 0.98 \\
\hline Age & -0.551 & -0.203 & -1.763 & 0.08 \\
\hline Bystander response & -9.842 & -0.118 & -1.016 & 0.3 \\
\hline Time to ROSC & 818.531 & 0.226 & 1.973 & 0.05 \\
\hline Shockable rhythm & -1.685 & -0.018 & -0.157 & 0.87 \\
\hline Multiple correlation coefficient & $(\mathrm{R})=0.565$ & $\mathrm{R}^{2}=32.02 \%$ & $\mathrm{Ra}^{2}=26.36 \%$ & $<0.0001$ \\
\hline
\end{tabular}

\begin{tabular}{|l|c|c|c|c|}
\hline Multiple regression model & $\boldsymbol{\beta}$ coefficient & $\mathbf{r}$ coefficient & $\mathbf{t}$ Stat & p-value \\
\hline Norepinephrine dose & 38.808 & 0.327 & 1.971 & 0.04 \\
\hline Mean BP $<70 \mathrm{mmHg}$ & 12.325 & 0.107 & 0.909 & 0.36 \\
\hline Age & -0.057 & -0.015 & -0.133 & 0.89 \\
\hline Bystander response & 11.558 & 0.118 & 1.001 & 0.32 \\
\hline Time to ROSC & 410.47 & 0.148 & 1.266 & 0.2 \\
\hline Shockable rhythm & -51.236 & -0.424 & -3.948 & 0.0002 \\
\hline Multiple correlation coefficient & $(\mathrm{R})=0.556$ & $\mathrm{R}^{2}=30.96 \%$ & $\mathrm{Ra}^{2}=25.136 \%$ & 0.0001 \\
\hline
\end{tabular}

Figure 3. A. Association between norepinephrine dose and neuronal specific enolase (NSE) concentration on admission in the study population; B. Association between norepinephrine dose and NSE concentration 24 hours after admission in the study population.

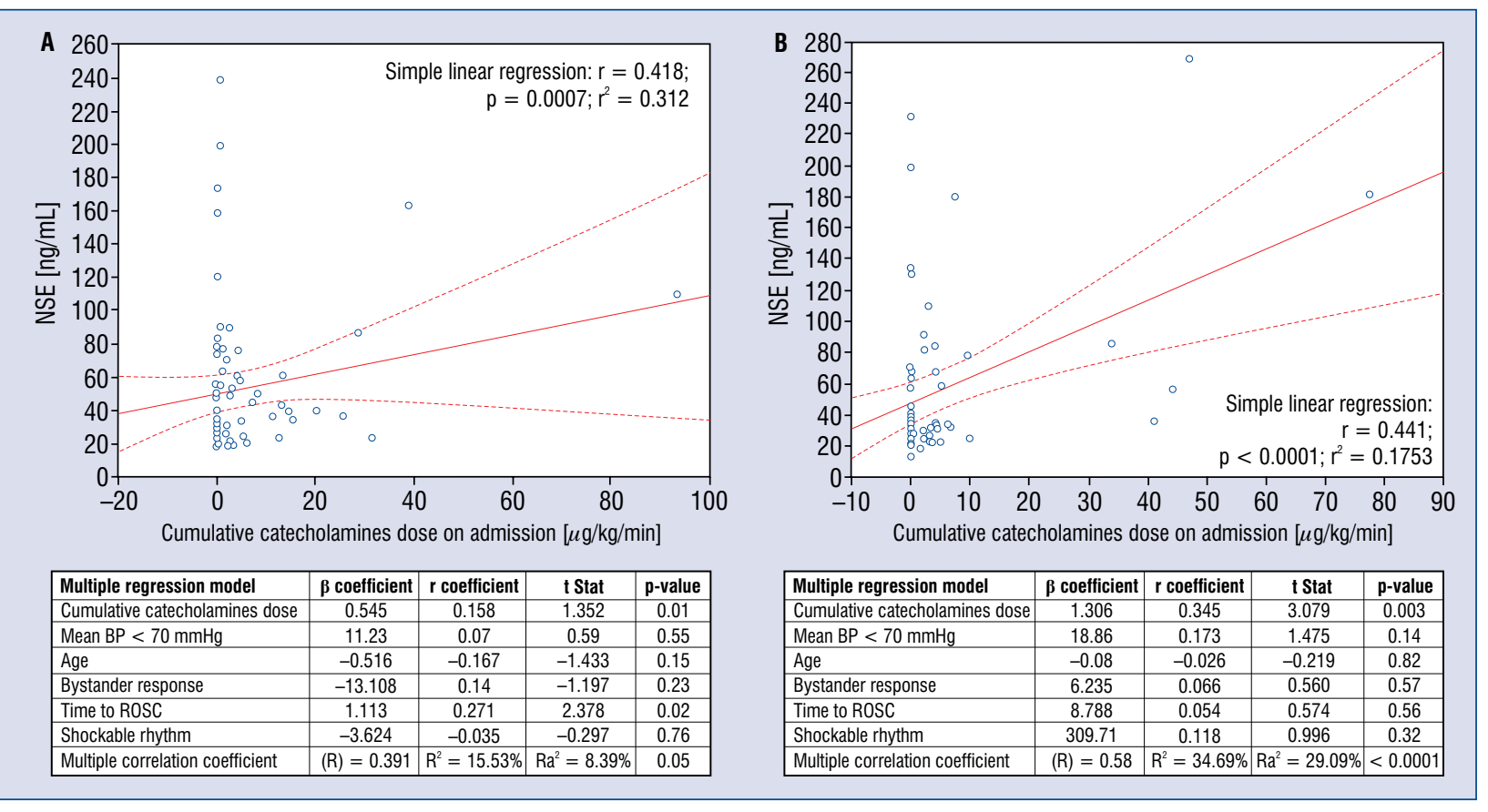

Figure 4. A. Association between cumulative catecholamines dose and neuronal specific enolase (NSE) concentration on admission in the study population; B. Association between cumulative catecholamines dose and NSE concentration 24 hours after admission in the study population. 
Table 3. The association between catecholamine doses and lactate, neuronal specific enolase (NSE) concentration in non-survivors in the Spearman correlation.

\begin{tabular}{|c|c|c|c|}
\hline $\begin{array}{l}\text { Correlations between catecholamines dose and lactate concentration } \\
\text { up to } 72 \mathrm{~h} \text { after admission }\end{array}$ & N pairs & $\mathbf{R}$ & $\mathbf{P}$ \\
\hline Lactate and norepinephrine dose on admission & 36 & 0.407 & 0.01 \\
\hline Lactate and cumulative catecholamine dose on admission & 63 & 0.487 & 0.02 \\
\hline Lactate and norepinephrine dose $24 \mathrm{~h}$ after admission & 33 & 0.443 & 0.009 \\
\hline Lactate and cumulative catecholamine dose $24 \mathrm{~h}$ after admission & 50 & 0.290 & 0.04 \\
\hline Lactate and norepinephrine dose $48 \mathrm{~h}$ after admission & 22 & 0.530 & 0.01 \\
\hline Lactate and cumulative catecholamine dose $48 \mathrm{~h}$ after admission & 41 & 0.491 & 0.001 \\
\hline Lactate and norepinephrine dose $72 \mathrm{~h}$ after admission & 14 & -0.166 & 0.56 \\
\hline Lactate and cumulative catecholamine dose $72 \mathrm{~h}$ after admission & 39 & -0.154 & 0.34 \\
\hline $\begin{array}{l}\text { Correlations between catecholamines dose and NSE concentration } \\
\text { up to } 72 \mathrm{~h} \text { after admission }\end{array}$ & N pairs & $\mathbf{R}$ & $\mathbf{p}$ \\
\hline NSE and norepinephrine dose on admission & 25 & 0.415 & 0.03 \\
\hline NSE and cumulative catecholamine dose on admission & 36 & 0.465 & 0.03 \\
\hline NSE and norepinephrine dose $24 \mathrm{~h}$ after admission & 20 & 0.442 & 0.03 \\
\hline NSE and cumulative catecholamine dose $24 \mathrm{~h}$ after admission & 26 & 0.398 & 0.04 \\
\hline NSE and norepinephrine dose $48 \mathrm{~h}$ after admission & 18 & 0.056 & 0.82 \\
\hline NSE and cumulative catecholamine dose $48 \mathrm{~h}$ after admission & 26 & 0.140 & 0.49 \\
\hline NSE and norepinephrine dose $72 \mathrm{~h}$ after admission & 9 & 0.066 & 0.86 \\
\hline NSE and cumulative catecholamine dose $72 \mathrm{~h}$ after admission & 25 & 0.331 & 0.10 \\
\hline
\end{tabular}

The present study has, for the first time, demonstrated that catecholamines dose over the first 24 hours of PCAS correlates independently with NSE concentration, with a particularly profound correlation in the non-survivor cohort. Although brain tissue perfusion and metabolism after OHCA is poorly investigated, previous studies suggest that brain circulation is, to some extent, independent from systemic circulation [30, 31] with NSE concentration being acknowledged as the best indicator for brain tissue injury and mortality predictor after OHCA [1, 2]. Notably, only one previous study tested the association between NSE concentration and early goal-directed hemodynamic optimization, aiming to improve one-year neurological outcome after OHCA [32]. Similar to the current results, research showed that hemodynamic optimization with norepinephrine was related to higher NSE concentration during the first 5 days after OHCA, but with no late neurological consequences [32]. One-year neurologic outcomes however, do seem to be quite a distant endpoint for an assessment of the direct effect of catecholamines in the early and intermediate course of PCAS. Further investigation is required to clarify whether this association truly reflects an adverse effect of norepinephrine or whether it simply reflects a wash out phenomenon due to improved brain perfusion.

Finally, the present PSM findings suggest that catecholamines dose might be especially relevant for those with poor in-hospital prognosis after OHCA. Exogenous catecholamines have never been demonstrated to improve OHCA outcomes and the need for high doses of vasopressors was shown to be associated with increased mortality early after resuscitation $[1,2,4]$. Notably, care of patients after OHCA is time-sensitive, as most post-resuscitation deaths occur during the first 72-96 hours after the event $[1,2,20]$. It is therefore important to focus future studies on investigating proper management in the early course of PCAS, including type and dose of catecholamines.

\section{Limitations of the study}

The current study has several limitations. This was an observational study with a limited sample size, and thus, only a correlation can be reported, rather than an inference of causation between catecholamines dose and laboratory derangement. Furthermore, data collection was limited to the first 72 hours after OHCA with catecholamines dose and laboratory derangement assessed in selected time 
points only, providing only limited information on the complex interplay between catecholamines, hemodynamics and metabolism. Subsequently, the association between catecholamines doses and metabolic derangements were moderate in their power and the role of potential factors driving the use and dosage of catecholamines, including age, initial rhythm, down time, time to ROSC, blood pressure; though incorporated in the multivariable analyzes, has to be emphasized. Finally, metabolic derangements constituting only markers of default metabolism and should not be treated as a direct surrogate of organ failure.

Therefore, the noted association between catecholamines dose, laboratory derangement and mortality should be regarded as a starting point for further investigation.

\section{Conclusions}

Increasing dose of catecholamines, administered early after OHCA, is related with higher lactate and NSE concentration, which may suggest their importance for impaired tissue oxygen delivery, enhanced anaerobic metabolism and organ function, especially in patients with poor in-hospital prognosis.

\section{Conflict of interest: None declared}

\section{References}

1. Nolan JP, Soar J, Cariou A, et al. European Resuscitation Council and European Society of Intensive Care Medicine 2015 guidelines for post-resuscitation care. Intensive Care Med. 2015; 41(12): 2039-2056, doi: 10.1007/s00134-015-4051-3, indexed in Pubmed: 26464394.

2. Berg KM, Soar JM, Andersen LW, et al. Adult Advanced Life Support: 2020 International Consensus on Cardiopulmonary Resuscitation and Emergency Cardiovascular Care Science With Treatment Recommendations. Circulation. 2020; 142(16_suppl_1): S92-S9S139, doi: 10.1161/CIR.0000000000000893, indexed in Pubmed: 33084390.

3. Dellinger R, Levy M, Carlet J, et al. Surviving sepsis campaign: international guidelines for management of severe sepsis and septic shock: 2008. Crit Care Med. 2008; 36(1): 296-327, doi: 10.1097/01.ccm.0000298158.12101.41.

4. Dünser MW, Hasibeder WR. Sympathetic overstimulation during critical illness: adverse effects of adrenergic stress. J Intensive Care Med. 2009; 24(5): 293-316, doi: 10.1177/0885066609340519, indexed in Pubmed: 19703817.

5. Asfar P, Hauser B, Radermacher P, et al. Catecholamines and vasopressin during critical illness. Crit Care Clin. 2006; 22(1): 131-149, vii, doi: 10.1016/j.ccc.2005.08.007, indexed in Pubmed: 16399024.

6. Cooper BE. Review and update on inotropes and vasopressors. AACN Adv Crit Care. 2008; 19(1): 5-13; quiz 14, doi: 10.1097/01. AACN.0000310743.32298.1d, indexed in Pubmed: 18418098.
7. Bouhemad B, Nicolas-Robin A, Arbelot C, et al. Isolated and reversible impairment of ventricular relaxation in patients with septic shock. Crit Care Med. 2008; 36(3): 766-774, doi: 10.1097/ CCM.0B013E31816596BC, indexed in Pubmed: 18431265.

8. Monge García MI, Santos A, Diez Del Corral B, et al. Noradrenaline modifies arterial reflection phenomena and left ventricular efficiency in septic shock patients: A prospective observational study. J Crit Care. 2018; 47: 280-286, doi: 10.1016/j. jcrc.2018.07.027, indexed in Pubmed: 30096635.

9. Stamm C, Friehs I, Cowan D, et al. Dopamine treatment of postischemic contractile dysfunction rapidly induces calcium-dependent pro-apoptotic signaling. Circulation. 2002; 106(12_suppl_1), doi: 10.1161/01.cir.0000032896.55215.a0.

10. Vasquez A, Kern KB, Hilwig RW, et al. Optimal dosing of dobutamine for treating post-resuscitation left ventricular dysfunction. Resuscitation. 2004; 61(2): 199-207, doi: 10.1016/j.resuscitation.2004.01.002, indexed in Pubmed: 15135197.

11. Iscimen R, Cartin-Ceba R, Yilmaz M, et al. Risk factors for the development of acute lung injury in patients with septic shock: an observational cohort study. Crit Care Med. 2008; 36(5): 1518-1522, doi: 10.1097/CCM.0b013e31816fc2c0, indexed in Pubmed: 18434908.

12. De Backer D, Creteur J, Silva E, et al. Effects of dopamine, norepinephrine, and epinephrine on the splanchnic circulation in septic shock: which is best? Crit Care Med. 2003; 31(6): 1659-1667, doi: 10.1097/01.CCM.0000063045.77339.B6, indexed in Pubmed: 12794401.

13. Aninat C, Seguin P, Descheemaeker PN, et al. Catecholamines induce an inflammatory response in human hepatocytes. Crit Care Med. 2008; 36(3): 848-854, doi: 10.1097/ CCM.0B013E31816532BE, indexed in Pubmed: 18431272.

14. von Känel R, Dimsdale JE. Effects of sympathetic activation by adrenergic infusions on hemostasis in vivo. Eur J Haematol. 2000; 65(6): 357-369, doi: 10.1034/j.1600-0609.2000.065006357.x, indexed in Pubmed: 11168493.

15. Ensinger H, Weichel T, Lindner KH, et al. Are the effects of noradrenaline, adrenaline and dopamine infusions on VO2 and metabolism transient? Intensive Care Med. 1995; 21(1): 50-56, doi: 10.1007/BF02425154, indexed in Pubmed: 7560474.

16. Czerwińska-Jelonkiewicz K, Grand J, Tavazzi G, et al. Acute respiratory failure and inflammatory response after out-of-hospital cardiac arrest: results of the Post-Cardiac Arrest Syndrome (PCAS) pilot study. Eur Heart J Acute Cardiovasc Care. 2020; 9(4_suppl): S110-S121, doi: 10.1177/2048872619895126, indexed in Pubmed: 32004080.

17. Ferreira FL, Bota DP, Bross A, et al. Serial evaluation of the SOFA score to predict outcome in critically ill patients. JAMA. 2001; 286(14): 1754-1758, doi: 10.1001/jama.286.14.1754, indexed in Pubmed: 11594901.

18. Langhelle A, Nolan J, Herlitz J, et al. Recommended guidelines for reviewing, reporting, and conducting research on post-resuscitation care: the Utstein style. Resuscitation. 2005; 66(3): 271-283, doi: 10.1016/j.resuscitation.2005.06.005, indexed in Pubmed: 16129543.

19. Laurikkala J, Wilkman E, Pettilä V, et al. Mean arterial pressure and vasopressor load after out-of-hospital cardiac arrest: Associations with one-year neurologic outcome. Resuscitation. 2016; 105: 116-122, doi: 10.1016/..resuscitation.2016.05.026, indexed in Pubmed: 27283060.

20. Kakavas S, Chalkias A, Xanthos T. Vasoactive support in the optimization of post-cardiac arrest hemodynamic status: from pharmacology to clinical practice. Eur J Pharmacol. 2011; 667(1-3): 32-40, doi: 10.1016/j.ejphar.2011.06.002, indexed in Pubmed: 21693117. 
21. Overgaard CB, Dzavík V. Inotropes and vasopressors: review of physiology and clinical use in cardiovascular disease. Circulation. 2008; 118(10): 1047-1056, doi: 10.1161/CIRCULATIONAHA.107.728840, indexed in Pubmed: 18765387.

22. Tilley DG, Rockman HA. Role of beta-adrenergic receptor signaling and desensitization in heart failure: new concepts and prospects for treatment. Expert Rev Cardiovasc Ther. 2006; 4(3): 417-432, doi: 10.1586/14779072.4.3.417, indexed in Pubmed: 16716102 .

23. Modest VE, Butterworth JF. Effect of $\mathrm{pH}$ and lidocaine on betaadrenergic receptor binding. Interaction during resuscitation? Chest. 1995; 108(5): 1373-1379, doi: 10.1378/chest.108.5.1373, indexed in Pubmed: 7587445.

24. Jhanji S, Stirling S, Patel N, et al. The effect of increasing doses of norepinephrine on tissue oxygenation and microvascular flow in patients with septic shock. Crit Care Med. 2009; 37(6): 1961-1966, doi: 10.1097/CCM.0b013e3181a00a1c, indexed in Pubmed: 19384212.

25. De Backer D, Creteur J, Dubois MJ, et al. The effects of dobutamine on microcirculatory alterations in patients with septic shock are independent of its systemic effects. Crit Care Med. 2006; 34(2): 403-408, doi: 10.1097/01.ccm.0000198107.61493.5a, indexed in Pubmed: 16424721.

26. Levy B, Bollaert PE, Charpentier C, et al. Comparison of norepinephrine and dobutamine to epinephrine for hemodynamics, lactate metabolism, and gastric tonometric variables in septic shock: a prospective, randomized study. Intensive Care Med. 1997; 23(3): 282-287, doi: 10.1007/s001340050329, indexed in Pubmed: 9083230.

27. Levy B. Lactate and shock state: the metabolic view. Curr Opin Crit Care. 2006; 12(4): 315-321, doi: 10.1097/01. ccx.0000235208.77450.15, indexed in Pubmed: 16810041.

28. Kliegel A, Losert H, Sterz F, et al. Serial lactate determinations for prediction of outcome after cardiac arrest. Medicine (Baltimore). 2004; 83(5): 274-279, doi: 10.1097/01. md.0000141098.46118.4c, indexed in Pubmed: 15342971.

29. Arnold RC, Shapiro NI, Jones AE, et al. Multicenter study of early lactate clearance as a determinant of survival in patients with presumed sepsis. Shock. 2009; 32(1): 35-39, doi: 10.1097/ shk.0b013e3181971d47, indexed in Pubmed: 19533847.

30. Engrand N, Lebard C, Luis D, et al. Return of spontaneous circulation after an out-of-hospital cardiac arrest: An acute brain injury like others? Resuscitation. 2020; 153: 268-269, doi: 10.1016/j. resuscitation.2020.01.044, indexed in Pubmed: 32502574.

31. Sandroni C, D’Arrigo S, Nolan JP. Prognostication after cardiac arrest. Crit Care. 2018; 22(1): 150, doi: 10.1186/s13054-0182060-7, indexed in Pubmed: 29871657.

32. Ameloot K, De Deyne C, Eertmans W, et al. Early goal-directed haemodynamic optimization of cerebral oxygenation in comatose survivors after cardiac arrest: the Neuroprotect post-cardiac arrest trial. Eur Heart J. 2019; 40(22): 1804-1814, doi: 10.1093/ eurheartj/ehz120, indexed in Pubmed: 30895296. 